\title{
Diálogos y contrastes entre proyectos de desarrollo y modelos de salud. Experiencia y consideraciones en torno a los achuar de la Amazonía Ecuatoriana ${ }^{1}$
}

\author{
Dialogues and Contrasts Between Development Projects \\ and Health Models. Experience and Considerations \\ About the Achuar of the Ecuadorian Amazon
}

\author{
¿Quién de nosotros cree que los propios trastornos \\ corporales y la muerte que los sigue son sucesos \\ puramente neutros, tan sólo un evento insignificante \\ en la cadena infinita de las causas? \\ (Malinowski 1974: 9) \\ Montserrat Pulido-Fuentes \\ Universidad de Castilla-La Mancha \\ montserrat.pulido@uclm.es
}

\section{RESUMEN}

La ejecución de un programa de salud entre el pueblo achuar de la Amazonía Ecuatoriana, bajo las lógicas de la cooperación al desarrollo y del modelo biomédico occidental, redefine el modelo de salud de la sociedad en la que interviene; así como a sus agentes de salud. Las capacitaciones, las infraestructuras, los preceptos e indicaciones contribuyen en la construcción de un prototipo que relega la práctica terapéutica tradicional, las diferentes categorías de males, así como las explicaciones derivadas sobre el origen de las enfermedades, a pesar de mantener un discurso crítico y un marco teórico que busca la integración de todos los modelos. El presente artículo, trata de aproximarse al proceso de salud-enfermedad-atención de la población achuar, analizando las relaciones que se presentan entre los diferentes actores que participan en dicho proceso. Se analiza la aplicación de un proyecto de promoción de la salud, la emergencia de respuestas y estrategias tanto acomodaticias como de resistencia local. La etnografía recapitulada, trata de mostrar algunas reflexiones sobre la fragilidad en la formulación e implementación de programas de salud, al perdurar la falta de perspectiva local, así como la perspectiva del estado. También se muestran otras competencias culturales que apelan a la inclusión de estos grupos y de sus terapias en las políticas sanitarias, y no solo de forma retórica o como proyectos políticos,

\footnotetext{
${ }^{1}$ Agradezco las aportaciones de cada uno de los participantes en esta investigación. De modo especial agradezco al profesor Juan Antonio Flores Martos su dedicación y sus excelentes comentarios. De forma honorable quiero que este agradecimiento llegue a la comunidad achuar, por dejarme caminar a su lado. Los materiales etnográficos de este artículo forman parte de la tesis doctoral, véase Pulido 2014. Aunque este ensayo es original, obviamente se alimenta de análisis ya realizados
} 
—más allá de un mero rescate ideológico. A pesar de todo, se describe la inevitable hibridación y necesaria negociación entre los actores implicados en el proceso.

Palabras clave: Modelos de salud; Cooperación al desarrollo; Etnografía; Achuar; Ecuador.

\section{SUMMARY}

The implementation of a health program among the Achuar people of the Ecuadorian Amazon, under the logic of development cooperation and the Western biomedical model redefines the health model of society in which intervenes; and their health workers. The indications trainings, infrastructure precepts contribute to the construction of a prototype that relegates the traditional therapeutic practice, the different categories of evils, and the explanations derived on the origin of the disease, despite maintaining a critical discourse and a theoretical framework that seeks to integrate all models. This article tries to approach the process of health-disease-care Achuar population, analyzing the relationships that occur between the different actors involved in the process. The implementation of a project to promote health, emergency responses and strategies both accommodative and local resistance is analyzed. The recapitulated ethnography, tries to show some reflections on the fragility in the formulation and implementation of health programs, to endure the lack of local perspective and the perspective of the state. Other cultural skills that appeal to the inclusion of these groups and their therapies in health policies are also shown, and not only rhetorically or as political projects-beyond a mere ideological rescue. Nevertheless, the inevitable hybridization and necessary negotiation between the actors involved in the process described.

Key words: Health Models; Development Cooperation; Ethnography; Achuar; Ecuador.

Una tarde de domingo húmeda y calurosa, nada extraño por estas latitudes, con poco movimiento en la comunidad salvo la misa de la mañana ${ }^{2}$, que reúne a los seguidores en la iglesia, a decir bien a casi toda la comunidad, y un partido de fútbol a media tarde, el cual altera el silencio de la selva con gritos y alborozos, termina sobresaltada.

El día en el puesto de salud ha sido más bien "aburrido", apenas acuden pacientes por lo que se aprovecha para hacer balance sobre las actividades realizadas. Dada la tranquilidad se decide salir a pasear alrededor de la comunidad. Ha terminado el partido de fútbol y han vuelto del río casi todas las familias, así como los chicos y chicas internados e internadas en la misión. El día, a punto de despedirse, genera en el cielo cúmulos de nubes que colorean el atardecer.

De pronto se oyen gritos. Se escucha un gran revuelo no muy lejos, un grupo de vecinos se dirige a la casa del locutor de la radio el cual debe comenzar la sesión de la tarde en una hora. Aquella tarde Fulgencio no va a la radio, su hija pequeña sufre un episodio patológico por el encuentro repentino con algún espíritu o Iwianch $^{3}$. Se escucha decir, "corran, la hija de Fausta ${ }^{4}$ se ha muerto, están pidiendo auxilio". El personal de salud se encuentra una niña de tres años con pérdida de conocimiento, palidez de piel y mucosas, frialdad generalizada y no responde a órdenes verbales. El grupo se encamina hacia el puesto de salud. Fausta carga con su hija en brazos, con

\footnotetext{
${ }^{2}$ Véase Sánchez (2015) para un estado de la cuestión acerca del concepto de comunidad.

3 Término genérico que designa ciertas manifestaciones nefastas del mundo sobrenaturales y de la práctica chamánica (Descola 2005: 403).

${ }^{4}$ Los nombres de los informantes son ficticios para preservar su intimidad.
} 
paso sosegado llora sigilosamente, con un quejido ronco, y constante. El personal sanitario intenta que avance con la premura suficiente para actuar a tiempo. El padre, desfigurado, callado, apagado, cabizbajo, con la hija mayor al lado, sin responder a lo que le preguntan los sanitarios. Fausta recita algo que no se llega a entender, se les ve realmente afectados y en un abandono que no se alcanza a entender desde una visión occidental ${ }^{5}$. Caminan lentamente en un estado de conmoción, con la hija en brazos, como ofreciéndola al cielo y con la mirada perdida.

Durante el trayecto hacia el dispensario es inevitable recordar los buenos momentos disfrutados con esta mujer y su marido Fulgencio, el locutor y estudiante de magisterio. El camino diario al puesto de salud deja al margen izquierdo su casa, atrás quedan los intercambios de saludos más o menos tímidos, las miradas de complicidad, los días compartidos en las aulas con los más pequeños, las muestras de cariño y de sencillez. Incluso Fausta ha desvelado las virtudes de algunas plantas medicinales que usa y que ella misma cultiva, pese a sus iniciales reservas a divulgar sus saberes y farmacopea.

En el puesto de salud donde se encuentra la doctora Maura, se tumba a la niña en la camilla, se le examina minuciosamente y se le canaliza una vía venosa periférica. La exploración neurológica parece normal, por lo que no se aplica ninguna otra medida más que la observación. La señal de alarma está encendida, ante un cuadro que puede evolucionar de forma grave, los años de experiencia indican que hay que permanecer vigilante y mantener la calma. En pocos minutos se concentra toda la comunidad en el puesto de salud, a excepción de los chicos y chicas del internado. Sorprende la presencia de la hermana Rita y del hermano Florencio encargados del buen funcionamiento de la misión.

La niña recupera paulatinamente el estado de hipotonía, desde la perspectiva médica occidental parece haber sufrido una importante crisis convulsiva. Se les pregunta a los padres si ha tomado alguna planta, o algún remedio y se descarta una posible intoxicación por fármacos, u otra sustancia. Se acompaña al padre a la casa, la médico con más experiencia insiste en descartar cualquier posibilidad, puesto que los padres, como otras veces ha ocurrido, estaban recogiendo leña y dejaron a las niñas jugando alrededor de su hogar; han sido sorprendidos por el cuadro clínico de la criatura fuera de la casa, desconocen por tanto lo que puede haber ocurrido durante su ausencia. En la casa, alrededores y donde se encontraba la niña no hay rastro de nada que indicase pudiese haber sido el desencadenante del cuadro, todo está en su lugar, los fármacos que almacenan en casa están intactos.

Con voz tenue el padre relata la explicación sobre las causas del episodio que acaba de tener lugar:

Nosotros sabemos decir que cuando pasa esto es porque ha visto al diablo y así saben quedar pero, ¿por qué pasa esto a mi hijita? —se pregunta constantemente- igual ustedes no creen en todo esto, ni en brujos, pero nosotros así sabemos creer, también le pasó a mi hijita mayor, ¿Por qué sabe pasar a mis hijitas?, la niña comió bien, sajino que yo mismo cacé a la mañana, estaba comiendo choclo — muestra el maíz- porque con la otra decían sino había comido, sino sabíamos cuidar....

5 El ritmo lento y pausado, el sosiego y la tranquilidad en este tipo de situaciones no ha sido lo que el modelo biomédico ha reforzado, donde la alarma (social) y la atención urgente apremian. Véase Pulido 2014. 


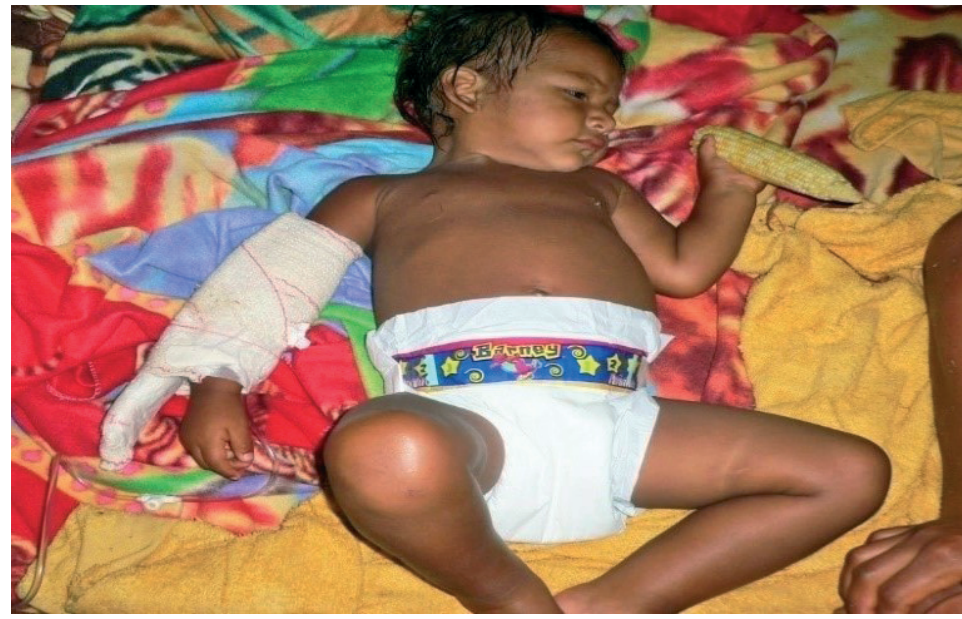

IMAGEN 1.-Niña que ha sido ahumada por el Tsuakratin y lavada por la mamá después de sufrir crisis convulsivas según las categorías del modelo biomédico o Pajú, visión aterradora de diablos conforme a los criterios del modelo de salud achuar. Fotografía de la autora.

Entonces coge algodón y se vuelve al puesto de salud, al verle llegar la doctora le dice: "dale con algodón si quieres", Fulgencio calla y no dice nada.

Toda la comunidad mastica un único pensamiento: "ha venido a llevarse a la niña el espíritu de un muerto encarnado en un animal o en los fantasmas antropoides"; lo que estos pobladores reconocen como iwianch. Se trata de la posesión de un niño por el wakan de un muerto ${ }^{6}$, suerte de contagio espiritual llamada imimketin. (Descola 2005: 231). Estos espíritus tienen envidia de los vivos y se llevan a uno de ellos por un tiempo, teniendo predilección por los niños puesto que son más débiles.

Cuando la niña recupera la conciencia, Valeriano el Tsuakratin ${ }^{7}$, está en el puesto de salud, para procurarle los cuidados que considera más adecuados; trata de ahumarla con el humo del tabaco, untarla con ceniza tibia hasta teñirla de negro para

\footnotetext{
${ }^{6}$ El wakan de los achuar se corresponde aproximadamente con lo que la filosofía occidental y la teología cristiana llaman alma, componente de la persona, dotada de existencia propia y susceptible de separarse de su soporte temporalmente durante los sueños, los trances visionarios, o definitivamente durante la enfermedad. La muerte para los achuar, resulta de la decisión voluntaria del wakan de separarse del lugar donde se había establecido poco después de la concepción del feto; los muertos son eternos insatisfechos y los niños resultan un receptáculo soñado por la permeabilidad a las influencias del entorno y el estado inacabado de su wakan; el alma de los muertos encuentra en estos cuerpos una ventana al mundo.

${ }^{7}$ Según el vocabulario jíbaro que Descola (2005: 402) elabora, el término tsuakratin califica al chamán "curandero". Tsuak, es el "remedio".
} 
que el espíritu no la vea de nuevo y fortalecer así su wakan. La cura no siempre es efectiva, algunos niños mueren por esta causa. El resto de las mamás se ocupan de cuidar a sus hijos puesto que el diablo puede venir por ellos, y se escucha: ... "vengan a la casa que va a venir el diablo".

La decisión médica de sacar a la niña al hospital de Macas para el estudio por imágenes de lo ocurrido no se lleva a cabo, no parece tener sentido para los padres. El encuentro con los padres y con su hija, meses después en la ciudad de Macas, obliga a asegurarse que es aquella niña, debilitada, la que corre cargada de envases de plástico vacíos para llevarlos "dentro" y que le sirven de juego en esos momentos. Refieren que no ha vuelto a ocurrir ningún otro episodio, se han marchado de aquella comunidad a otra donde el locutor ha empezado a trabajar como profesor; no han realizado ninguna de las recomendaciones que la doctora les ha indicado.

\section{APROXIMACIÓN AL TERRENO}

La aproximación desde la etnografía al proceso de salud-enfermedad-atención de la población achuar, permite confrontar los modelos de salud achuar y aquéllos importados al área de Morona Santiago por la cooperación al desarrollo y el Estado ecuatoriano. Se trata, pues, de analizar las relaciones que se presentan entre los diferentes actores que participan en dicho proceso, sobre la manera de concebir e interpretar la medicina, la salud y también la enfermedad, y cómo se intercambian roles y perspectivas con la inclusión de la medicina occidental dentro del ámbito tradicional de este pueblo indígena. La aplicación de un proyecto de promoción de la salud, la emergencia de respuestas y estrategias tanto acomodaticias como de resistencia local muestra algunas reflexiones sobre la fragilidad de los mismos. A pesar de todo, se describe la inevitable hibridación y necesaria negociación entre los actores implicados en el proceso.

En una parte de la frontera que separa Perú y Ecuador, se encuentra una zona de selva amazónica donde perviven pobladores jíbaros o aínts, concretamente es población achuar, la que forma parte de esta investigación?. Los sistemas médicos y prácticas sobre salud son uno de los aspectos menos conocidos de la etnografía achuar y de los grupos jíbaros en general (Uriarte 2007; Descola 2005; Warren 1994).

La parroquia Huasaga, que recibe el nombre del río que la atraviesa, es la única de la provincia de Morona Santiago (Ecuador), y más concretamente del cantón Taisha con población achuar. En el año 2009 se crea una nueva parroquia bajo el nombre de Pumpuentsa, también de población achuar. Las otras dos parroquias del cantón son Makuma y Tuuthinensha, de población shuar. Se estima un total de población alrededor de 6.000 individuos (Uriarte 2007: 13) ${ }^{10}$.

\footnotetext{
${ }^{8}$ Las categorías "dentro" y "fuera" son expresiones empleadas por la gente local, haciendo referencia al espacio respecto del límite de selva propiamente dicha, marcado por la difícilmente penetrable vegetación, es decir cuando se traspasa la cordillera Cutucú, lo que implica que en un traslado en avioneta nos adentramos en la selva y al salir de este territorio nos encontramos fuera.

9 El territorio actual de los achuar está dividido a un lado y otro de la frontera demarcada por el Protocolo de Río de Janeiro en 1942 entre estos dos países.

${ }^{10}$ Censo de la organización achuar ecuatoriana FINAE (Federación Interprovincial de la $\mathrm{Na}$ cionalidad Achuar del Ecuador) para el año 2005. A partir de abril de 2005 adopta el nombre
} 
Desde un punto de vista sanitario, la parroquia Huasaga está dividida en cuatro áreas de salud: Ipiak, Wampuik, Pumbuentsa y Vichim, con sus comunidades de influencia correspondientes. En cada una de estas cuatro comunidades se ubica un puesto de salud, gestionado por auxiliares de enfermería, trabajadores del Ministerio de Salud Pública Ecuatoriano. Algunos disponen de microscopistas que dependen del SNEM ${ }^{11}$. Estos cuatro puestos son coordinados desde el subcentro de salud que hace las veces de un pequeño hospital, ubicado en la misión salesiana de Wasakentsa, siendo dirigido por la doctora Maura —una médica colona que ha estado trabajando con los achuar muchos años y que decide entrar en dicho centro, a raíz de la invitación de los misioneros.

En la ciudad y capital cantonal de Taisha está el hospital de referencia para la población achuar; las particularidades de esta ciudad, comunicada solo por vía aérea con las otras comunidades y con el resto de ciudades de la provincia y país, hacen que en muchas ocasiones los pacientes sean evacuados al Hospital Provincial de Macas (capital de la provincia), ambos pertenecientes al Ministerio de Salud Pública.

La medicina indígena cuenta con sus propios medios de diagnóstico y recursos terapéuticos, entre los cuales destacan las ceremonias rituales o el uso de diversas plantas medicinales. Un tercer escalón en la medicina achuar lo componen todos los enseres, fármacos, mobiliarios, útiles, remedios y lenguajes, que la medicina occidental ha acarreado con las mejores intenciones (Pulido 2014). El panorama de la medicina indígena se muestra incompleto si no incluimos en él el uso que los indígenas hacen de la biomedicina.

Desde el Ministerio de Salud Pública solo se ha conseguido que, de forma temporal, haya algún médico y profesionales de enfermería en alguno de los puestos de salud, los cuales terminan marchándose, pues no "se acostumbran a este modo de vida". En este sentido, "se intenta compensar al personal de salud que trabaja en estas zonas", aunque se ha retirado un suplemento económico que se ha estado aplicando durante un tiempo. Mientras, las ONG, fundaciones y otras instituciones con modelos teóricos que contemplan la diferencia y la convivencia entre distintos, plantean proyectos de desarrollo con personal cooperante y voluntario. Las principales líneas de acción del proyecto mencionado se dirigen a la capacitación y refuerzo de una red de promotores de salud, actividades médico-preventivas, actividades formativas y de promoción orientadas a las familias y a la población escolar. Se trata coordinar las actividades con el Ministerio de Salud Pública y establecer alianzas entre los diversos actores involucrados en los procesos de salud-enfermedad-atención, así como en la inversión en infraestructuras.

Los razonamientos que encuentra la población al elegir el itinerario más adecuado entre los que cada modelo de salud ofrece, responde a un proceso de construcción. En palabras de Byron Good "las personas que tienen acceso a un sistema médico plural, no eligen simplemente una entre las formas alternativas de curación sino que se inspiran en todas ellas" (2003: 281).

\footnotetext{
definitivo de Nacionalidad Achuar Ecuatoriana (NAE). Esta misma organización en el año 2010, confirma una población entre 6.000-7.000 individuos.

${ }^{11}$ Personal dependiente del SNEM (Servicio Nacional de Erradicación de la Malaria), capacitado en la recogida y análisis de muestras, dirigido principalmente para el diagnóstico diferencial de malaria.
} 
Al mismo tiempo, el pueblo achuar realiza sus quehaceres diarios. Las mujeres, además del cuidado de los hijos, son las que atienden las chacras o huertas, de las que extraen los principales productos que les permite subsistir, junto a la caza y a la pesca, tareas encomendadas al hombre. Utilizan el sistema de tala y quema, el hombre prepara la tierra para que la mujer siembre. Conciben la horticultura sobre el modelo de una relación de consanguinidad entre las mujeres y las plantas que cultivan, mientras que la caza pasa por el establecimiento de un lazo de alianza entre los hombres y las presas (Descolá 2005: 159).

El suelo que ocupa la misión salesiana es de la NAE, así como las infraestructuras construidas, tales como Centros Médicos, el Centro de Formación de Promotores o el Centro de Promoción de la Cultura achuar ${ }^{12}$, que en Wasakentsa mantiene un sistema de internado para poner la educación al alcance de todas las comunidades.

Este es el contexto donde una organización española diseña y ejecuta un proyecto de cooperación internacional de promoción de la salud, desde las lógicas de la

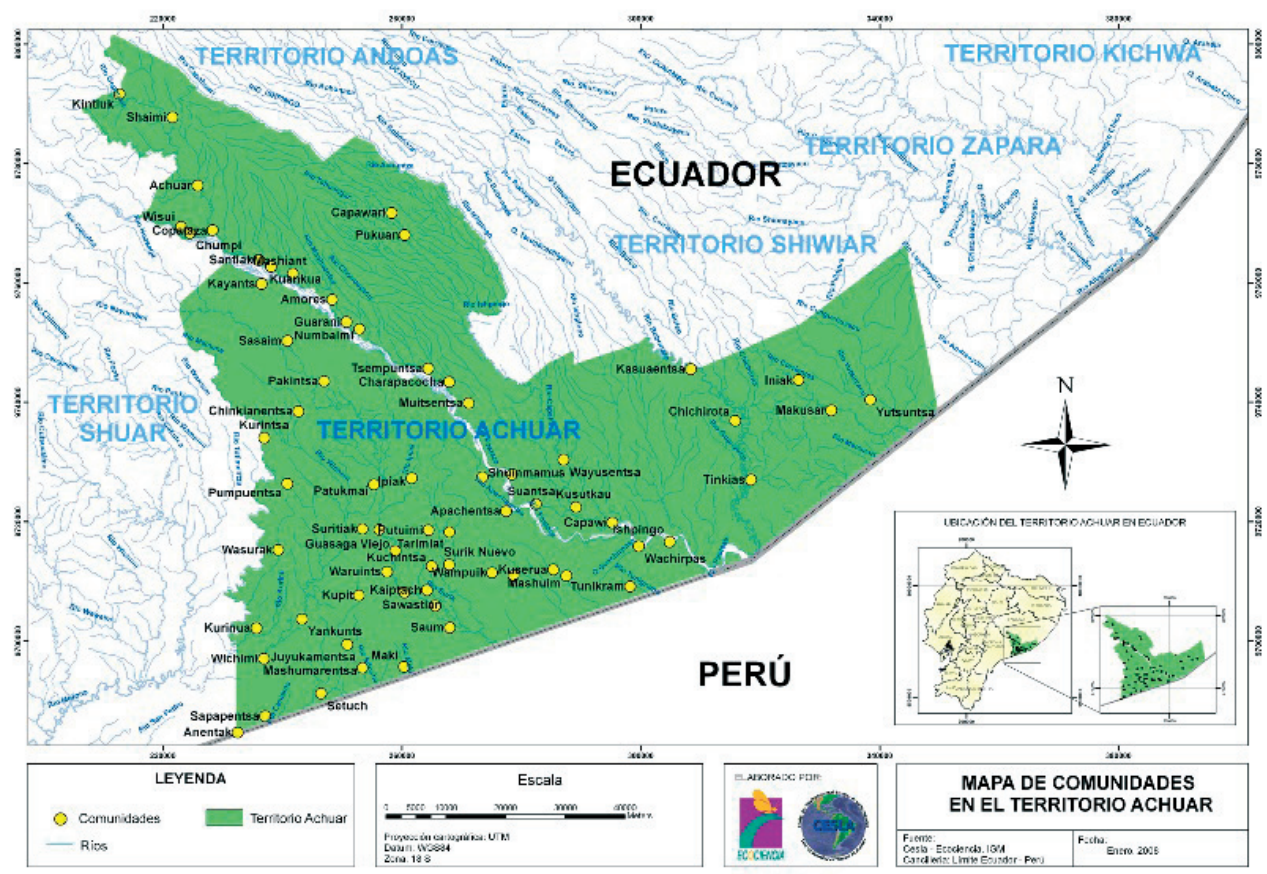

IMAGEN 2.-Mapa de ubicación geográfica. Fundación Ecociencia.

\footnotetext{
${ }^{12} \mathrm{El}$ sistema fiscomisional se fundamenta en un convenio de colaboración entre el Estado y las Misiones Católicas. Este sistema educativo proporciona la educación primaria hasta el noveno nivel (los seis grados y los tres años de ciclo básico) en casi todas las comunidades. El ciclo diversificado con Bachillerato en Ciencias de la Educación funciona en el Centro de Promoción de la Cultura achuar en Wasakentsa, con sus extensiones en Wampuik y Pumpuentsa. Para poner la educación superior al alcance de la juventud achuar, en Wasakentsa se ha constituido una extensión de la Universidad Politécnica Salesiana.
} 
biomedicina occidental y de la cooperación al desarrollo. El trabajo se lleva a cabo en colaboración con la contraparte local de origen religioso, y que nace en 1996 para ayudar a la población achuar en este territorio.

Esta investigación tiene un diseño etnográfico, y los datos se han recogido en el trabajo de campo realizado en el Alto Chankuap, en la parroquia de Huasaga, provincia Morona Santiago —Ecuador-, con población achuar y durante estancias intermitentes entre los años 2008 y 2010. Wasakentsa, Wampuik y Wichim han sido los puntos de partida al resto de comunidades.

La condición de la investigadora de enfermera "cooperante" ha permitido tener acceso a determinados espacios que de otro modo no hubiera sido posible, que ha condicionado la perspectiva ${ }^{13}$. Se ha tomado conciencia de lo que supone tener interiorizados años de experiencia profesional — como enfermera— en el ámbito occidental y de lo complicado de despojarse del "uniforme cultural".

Etnógrafa, cooperante, enfermera... los distintos roles de la investigadora contribuyen en la riqueza del análisis. Al participar como voluntaria en la organización que ejecuta un proyecto de cooperación internacional al desarrollo y realizar este trabajo de investigación, siendo al mismo tiempo sujeto y objeto de estudio, se ha podido ampliar la mirada y la profundidad de la misma. Otras cuestiones más delicadas, como los dilemas éticos también aparecen en el proceso ${ }^{14}$.

\section{EL PROCESO DE ENFERMAR ACHUAR Y EL ENCUENTRO CON PERSONALIDADES DE SABIDURÍA ANCESTRAL}

Un postulado fundamental de la cosmovisión achuar es que toda enfermedad, y sobre todo la muerte, es resultado de un acto chamánico premeditado. Este axioma presenta dos excepciones, una tradicional —el asesinato físico y directo- y otra moderna - que corresponde a las epidemias y muertes causadas por las enfermedades de los "blancos civilizados"-, lo que se denomina sunkúr ${ }^{15}$, evadiendo por tanto explicaciones chamánicas (Uriarte 2007: 101). Estas dos grandes categorías de males son descritas también por Descola (2005: 233), denominados tunchi los provocados y sanados por chamanes y los sunkúr, todo el resto. Éstos últimos solo pueden ser curados por el hombre blanco y por la medicina moderna. Todos los demás han de ser curados por un wawék o por un wishín ya que han sido ellos quienes los han causado. La diferencia depende de muchas circunstancias y del contexto, no habiendo una

\footnotetext{
${ }^{13}$ El uso indiscriminado y generalizado del término cooperante, se ha extendido a toda persona que participa en algún proyecto o programa de cooperación internacional al desarrollo, independientemente del contrato establecido con la entidad correspondiente. Para este desempeño se requiere cualificación, en contraste con el voluntario para el que teóricamente $-\mathrm{y}$ no en la práctica pues también es condición - no se solicita. Esto ha llevado a la investigadora a utilizar el término de "cooperante" como un genérico, que en su uso extendido abarca dentro de él también a la figura del voluntario sin apenas diferenciación con él.

${ }^{14}$ Ver Pulido (2016). En prensa.

${ }^{15}$ Los términos usados en idioma achuar aparecen con grafías distintas respetando las diferentes ortografías utilizadas por los diversos autores y fuentes en relación a las categorías de males así como las figuras que lo resuelven.
} 
distinción clara entre "brujería" y "enfermedad". Muchos de los sunkúr resultan de las maniobras de un hombre o un espíritu, y como los tunchi, pueden ser remitidos a causas externas. En ambos casos los achuar ubican su origen entre los otros y, cualquier sunkúrque no se resuelve con el tratamiento es reinterpretado como un tunchi.

Según el autor francés, no son los síntomas lo que permite diferenciar estas dos categorías, sino que es la resistencia a las técnicas no chamánicas de curación lo que determina que se trata de un tunchi, aun cuando el origen accidental esté probado. La eficacia de las terapias no depende tanto de las propiedades inherentes al remedio, como de las cualidades de quien lo administra y de las condiciones en las cuales se desarrolla la escena.

El estudio de Descola, sugiere que la procedencia terapéutica del modelo chamánico puede explicar el hecho de que los límites entre unas y otras dolencias no quedan claramente delimitados, con un modelo gobernado por dos principios, la exterioridad de la causa del mal y las semejanzas entre éstos y los agentes de curación (ibid.: 235). Esto lleva a determinar que toda enfermedad es causada por un individuo claramente diferenciado, e implica que debe resolverse por el responsable de su desencadenamiento, por algún análogo o por un extranjero, más alejado que el origen del mal.

Los achuar distinguen tres tipos de chamanes, según Uriarte (2007: 101). El wawék, brujo o hechicero oculto, solo causa daño por medios supra naturales. El tsuak que es un curandero médico que lleva a cabo de forma clara, abierta sus prácticas terapéuticas, que son reconocibles y valoradas por la población. Y el wishín con poderes supranormales tanto para curar como para matar, es la figura chamánica más extendi$\mathrm{da}$, convertidos en mediadores entre los espíritus y la sociedad achuar.

En diferentes encuentros con Valeriano al preguntarle por las terapias que aplica, no se reconoce como chamán, él siempre se presenta como Tsuakratin. En los intentos por hacerse entender a partir de las preguntas que se le formulan, con cierta dificultad de comprensión, además del desconocimiento de la lengua local, hace la traducción que considera más apropiada y se define como enfermero. Además, ejerce también de etserín o catequista en la misión. Sin embargo, los miembros de la comunidad cuando se refieren a Valeriano, se dirigen a él como chamán o le aluden por su nombre. Han sido varios los informantes los que han negado su condición de chamán, lo refieren a un pasado no muy lejano, asegurando no ejercer como tales.

La población achuar, indica la desaparición de estas figuras en sus comunidades relevantes en otros tiempos. Al mismo tiempo, no descartan recurrir a ellos para encontrar la cura o el remedio de sus males en las ocasiones que son necesarias, para lo cual se desplazan a las comunidades donde aún "perduran", resaltando de nuevo la significación de lo foráneo en la eficacia de los cuidados. En este sentido, han sido frecuentes los casos que siendo atendidos en los puestos de salud han recibido de forma simultánea la atención de alguno de estos sabios y poderosos hombres.

Los chamanes son, sobre todo en la parroquia Huasaga, teóricamente cada vez menos numerosos debido a tres motivos principalmente: las actividades misioneras, la introducción de la medicina moderna y los riesgos que conlleva la profesión chamánica misma (Uriarte 2007: 101). Ocupan el lugar más alto en la estratificación social y económica, aplican sus servicios a cambio de encargos o recursos también valiosos, lo que contribuye a disfrutar de dicha posición privilegiada en la sociedad achuar. Con cierta frecuencia se escucha hablar sobre los costes de los servicios de los chamanes. 
También se hace alusión al engaño y la estafa que algunos hombres sufren en este sentido. En Macas, la capital de la provincia Morona Santiago, se encuentra una población muy numerosa de chamanes, cuya actividad es muy intensa y muy solicitada. Algunos de ellos refieren haber viajado a Europa y Estados Unidos a ofrecer sus servicios a cambio de cobros suculentos ${ }^{16}$.

Al preguntar a los alumnos de las escuelas y de los estudios de diversificado sobre su interés en ser chamán, todos dan una respuesta negativa. Se trata sin duda de una posición ambivalente: por un lado, se reconoce su actividad como generadora de enfermedades, venganzas y muertes; y, por otro lado, admiten que son la única defensa ante las agresiones místicas de los enemigos. A pesar del alto riesgo implícito en el ejercicio de tal profesión, el rol chamánico ejerce un gran atractivo entre los jóvenes achuar. Se observa como gran número de las monografías que los alumnos al terminar los estudios de diversificado deben leer, se inclinan en el estudio de estos hombres poderosos ${ }^{17}$. En algunas conversaciones con los más jóvenes estos dan cuenta de la emoción que despiertan estas figuras. Se deleitan hablando de sus cualidades y de sus poderes mágicos, se posicionan en una distancia no muy lejana, reconociendo su ambivalencia y sus riesgos, los cuales frenan el seguir sus pasos. Algunos hablan con admiración de los antiguos chamanes que hay en la familia ${ }^{18}$, así como del proceso que deben realizar para alcanzar ese estatus, que de una forma un tanto confusa conocen y relatan, refieren que algunos ya han muerto, otros han tenido que huir y salir de la comunidad y saben que su regreso puede suponerles la muerte.

\section{"LOS INDÍGENAS SOLO QUIEREN LAS AVIONETAS PARA IR AL CHAMÁN"}

Las figuras sociales precolombinas que se hacen cargo de la transmisión de los saberes se han transformado. Ventura i Oller (2008) señala que las figuras de poder desaparecen, quedando la figura del chamán en la clandestinidad, asumiendo estas personas muchos de aquellos roles. Los chamanes mantienen su concepción de la enfermedad y su particular forma de relacionarse con la naturaleza. En el contexto Amazónico, el chamán, es un especialista en las relaciones simbólicas con el exterior. El poder chamánico deriva de fuentes que están fuera del grupo, y mientras "más remota la fuente, más fuerte el poder» (Taylor 1996: 145).

La región del alto Amazonas, desde épocas remotas ha establecido sistemas de intercambios comerciales que conectan las tierras bajas a los Andes y al litoral Pacífico. Dichos intercambios, han tenido especial relevancia, manteniendo cierta homogeneidad debido al proceso histórico de clandestinidad, aporte hispánico, desaparición

\footnotetext{
${ }^{16}$ Casi todos ellos de origen shuar y quechua, reconocidos entre la población achuar por sus poderes chamánicos.

${ }^{17}$ Los estudios de diversificado equivalen a los estudios de bachiller. El acceso a las monografías es restringido, y hay que solicitar varios permisos. Se ha tenido en cuenta que los trabajos están orientados por religiosos. Las percepciones, las descripciones y los datos que se reflejan en estas monografías da cuenta de la atracción señalada.

${ }^{18}$ En muchas casas se observan animales domésticos de diversa índole, que representan la fracción de criaturas que componen la corte de familiares que los chamanes llaman pasuk, término genérico que designa a los espíritus auxiliares del chamán (Descola 2005: 318).
} 
de espacios y revitalización del chamanismo como mecanismo de resistencia, más allá de una mal entendida aculturación, evitando así reducir una tarea por excelencia de los chamanes, la traducción, a un mal comprendido sincretismo (Ventura i Oller 2008; Chaumeil 2004).

En el mismo sentido, la concepción de la enfermedad como algo exógeno, junto con el énfasis puesto en las causas sociales e intencionales de la misma, más que en los síntomas o en las causas de origen biológico o naturales, dibuja un panorama donde los agentes patógenos se materializan en diversas formas. Los dardos mágicos, tsentsak entre los jíbaros ${ }^{19}$, no aparecen representados en ninguna otra parte mejor que en las regiones del alto y medio Amazonas (ibid.: 266). El chamán achuar, actúa a distancia por medio de estos proyectiles invisibles y adquieren el poder a través de los tsentsak que han conseguido de otros chamanes en rituales de transmisión de poderes que requieren ayuno, celibato y el uso de Ayahuasca como alucinógeno. También se consiguen al extraerlas del cuerpo de la persona afectada. Estas flechas o tsentsak son las que pueden curar, embrujar o enfermar, consideran que si vienen de lejos son más poderosas. ¿Esto puede explicar que busquen nuestras medicinas occidentales?

El chamán es casi siempre un hombre de otra familia que administra el tsuak, el remedio más comúnmente utilizado es el tratamiento con tabaco (Descola 2005: 237)20. Este tipo de tratamientos, incluidos los que proceden de los botiquines, deben ser administrados en condiciones de ayuno, tanto por el que lo recibe como por el que lo administra. Alrededor de estos rituales, se encuentran varios elementos mágicos que están asociados con la fe en su eficiencia (Malinowski 1974: 84). Hay música, esfuerzos fonéticos, imitaciones de sonidos naturales, cantos alegóricos, se recitan anent o encantamientos cantados, que describen la metamorfosis que el chamán sufre y los poderes que moviliza. Se invoca el deseado propósito. En la magia de curación, el hechicero evocará cuadros de perfecta salud y fuerza corporal. No faltan las alusiones mitológicas, las referencias a los antepasados y a los héroes de la cultura de los que se ha heredado ese saber. Y esto nos lleva a lo que tal vez es el punto más importante de este tema, o sea, el escenario tradicional de la magia (ibid: 93).

Más allá de la cordillera del Cutucú ${ }^{21}$, el Ministerio de Salud Pública incorpora a finales del siglo pasado los servicios de salud intercultural como departamentos específicos en los ministerios provinciales. Se pone en práctica el desarrollo de las medicinas tradicionales, alternativas y complementarias, para ello se lanzan campañas de sensibilización. En el año 2009, dentro del proceso de normatización del sistema nacional de salud, se crea el subproceso de medicina intercultural, con el propósito de

\footnotetext{
${ }^{19}$ El nombre fue aplicado después a los dardos de cerbatana, arma de cacería por excelencia de las sociedades del alto Amazonas; luego, por extensión, a los dardos-mágicos de los chamanes. Entre los jíbaro se emplea el mismo término para los dos tipos de dardos, otros grupos marcan la diferencia. Presenta muchos paralelismos con la caza, principal actividad de los hombres. Ser un gran cazador genera también reconocimiento social y estatus.

${ }^{20}$ Lo puede hacer soplando (umpuntrutin) el aire, el humo del tabaco, bien sobre el propio cuerpo, o sobre algún brebaje preparado que ingerirá el paciente. Otra forma de aplicar el remedio es chupando (muikuntratin) la parte afectada para extraer el mal o barriendo. Así como barriendo (japirtin), para disipar o paliar la enfermedad.

${ }^{21}$ Sistema montañoso que forma parte de la cordillera suboriental y que se extiende desde el río Pastaza hasta el río Santiago.
} 
desarrollar un modelo de salud intercultural que conlleve el Sumak Kawsay (Buen Vivir), Penker-Pujustin.

Una de las traducciones de este modelo, en la provincia Morona Santiago, ha sido el sistema de registro elaborado con el objetivo de identificar las figuras tradicionales de salud. Esto se realiza a través de un cuestionario en el cual se recogen datos personales, años de experiencia, estudios realizados, comunidad en la que viven, medios de diagnóstico y tratamiento de enfermedades culturales. El coordinador del servicio de salud intercultural Milton Shiwiach, señala que éstas, entre otras observaciones, deben ser cumplimentadas por todos aquellos que afirman realizar algún tipo de tratamiento, para reconocer a las diferentes figuras de sabiduría ancestral y tratar de rescatarlas e incorporarlas en el sistema de salud.

Aquí no tenemos recurso humano de la zona achuar, para viabilizar..., son políticas de salud, la de coacción cultural que los servicios que se brindan desde el Ministerio, es por eso que se hace la búsqueda de sanadores.

Bajo el paraguas de la interculturalidad y como estrategia política se trata de equiparar las figuras chamánicas a los terapeutas médicos. Estandarizar patrones de chamanes, homogeneizarlos bajo la lógica del sincretismo y la aculturación, como en tiempos pasados pero con políticas actualizadas; deja al margen las concepciones que sobre el proceso de salud-enfermedad-atención tiene la población achuar y se descuida el fenómeno del chamanismo. Los chamanes, alejados de este organigrama mencionado, apenas visibilizados, no entran en la arena política. Entienden que su hegemonía se mantiene, perdura y está interiorizada, puesto que su marco de actuación va mucho más allá de la medicina y descartan la existencia de rivalidad.

Desde algunos de los departamentos de salud intercultural tratan de integrar las prácticas de los chamanes en los hospitales, reconocerlas, y validarlas. Este es el caso del vecino Hospital de Puyo, en la provincia de Pastaza, que también atiende población achuar ${ }^{22}$. Al frente de este hospital encontramos unos dirigentes "sensibilizados" con el problema de salud intercultural que presenta su área de influencia. Algunos de ellos se someten a tratamientos con los chamanes para conocerlo de "primera mano". Se trata de capacitar al personal biomédico, se trabaja en diferentes líneas para superar miedos y dificultades encontradas entre el personal sanitario.

El otro trabajo es la direccionalidad de cómo hacer este trabajo, vamos a comenzar con la capacitación del personal de salud sobre el idioma achuar, todo el personal debe saber que el personal que debe llegar a nuestro territorio debe hablar achuar. (Milton Shiwiach).

Lo que se pretende es capacitar al personal en la cosmovisión indígena, primero hemos empezado por el personal de la dirección, porque son muchos, después jefes de servicio, para ellos es difícil porque han sido educados desde lo occidental y de que solo eso es lo que vale y es complicado. (Licenciada Lya, departamento de salud intercultural, PuyoPastaza).

\footnotetext{
${ }^{22}$ Este hospital integra personal para realizar funciones de intérpretes, permite la entrada de chamanes para realizar sus tratamientos o bien los pacientes pueden "salir" de la institución para recibir el tratamiento por parte de alguna de las figuras ancestrales. Asimismo dispone de un albergue para la estancia y la comida de los familiares y de un huerto medicinal.
} 
Yenni, directora de enfermería del hospital de Puyo, sabe que no todos acatan de forma incondicional estas propuestas:

Así saben decir... nos estamos ablandando, nos estamos sensibilizando, no es duda, es vergüenza, cómo yo puedo estar creyendo en este tipo de cosas y cayendo en hacer eso que no es mi competencia.

La dirección provincial de Morona Santiago muestra algunas discrepancias, las cuales presentan las fronteras diluidas entre los diferentes modelos de salud que la población achuar tiene a su alcance y, por tanto, utiliza en mayor o menor medida, con unos y otros sentidos, y que también son renegociados en los proyectos de cooperación al desarrollo.

Reunimos a un grupo de médicos y enfermeras y les preguntamos qué sienten cuando están con los pacientes indígenas, y se preguntó también a ellos... lo de integrar la figura del chamán en el hospital no, tiene una ambivalencia demasiado grande, cura o hace daño, la misma figura..., sí a la colaboración con el chamán pero de manera diferente, no compartiendo asistencia, no compartiendo el espacio..., un tiempo sí estuvo una figura de intérprete... (Doctor Palacios, director provincial, Morona Santiago).

Esta misma dirección, cuestiona el uso que la población achuar hace de las avionetas $^{23}$ cuando solicitan ser atendidos por problemas de salud, "los indígenas solo quieren las avionetas para ir al chamán". El Ministerio de Salud Pública asume los costes de las ambulancias aéreas cuando el proceso de salud se rige bajo los criterios del modelo alopático, es decir siempre que el paciente sea atendido en el hospital por personal biomédico. No se oponen a que otros agentes de salud intervengan en los espacios destinados para ellos, pero en tal caso el gasto de la avioneta deberá asumirlo el paciente.

Quedarnos en este nivel de asistencia, exhibe cierta falta de sensibilidad hacia otras formas de entender el proceso terapéutico, hacia otros conocimientos y sistemas de creencias. El personal de salud, a partir de criterios bio-fisiológicos, trata de valorar prácticas de orden simbólico, mientras la población traduce las prácticas médicas en función de una eficacia simbólica que no tienen (Michaux 2004: 118). La población achuar no reconoce el hospital como aquel espacio con competencia terapéutica, precisamente porque no alcanza ese estatus, tal y como lo señala Yenni:

El maltrato que espera recibir la población indígena en hospitales, postas de salud, botiquines dirigidos por personal sanitario colono, hace que sientan cierto rechazo a este tipo de medicina poco cuidadosa con la diferencia.

Entretanto, el resultado del encuentro entre las distintas concepciones y cosmovisiones no es de acercamiento, quizás sea difícil esta aproximación precisamente por las diferencias intrínsecas que subyacen. La situación de fuerte competencia con la medicina tradicional, algo usual entre este tipo de poblaciones, explica que los agentes de la biomedicina occidental se encuentren en una situación minoritaria y en franca desventaja, sin poder hacer medicina ni atender a pacientes (Flores 2004: 196).

23 También se las reconoce como ambulancias aéreas, las cuales están destinadas a la evacuación de pacientes desde las comunidades de dentro hasta las ciudades de fuera. Este tipo de costes, en ocasiones, forma parte de las ayudas recibidas por parte de diversas organizaciones e instituciones. 
Este tipo de propuestas ideológicas, políticas y retóricas (Flores 2011), más o menos institucionalizadas, se generan como respuesta a lógicas económicas, políticas y socioculturales - no locales- y conllevan un discurso intercultural. Se apuesta por la mejora de los resultados y el aumento de la eficacia en el acceso y el derecho a la salud de seres humanos de singularidad sociocultural. Se parte del diálogo entre las diferencias, un diálogo comprometido, delicado y espinoso, que implica un gran esfuerzo. Se percibe un proceso lento y con muchas entretelas que deberán emerger y renegociarse.

\section{INDEX NOMINUM GENERICORUM ${ }^{24}$}

El estudio de la eficacia de la curación chamánica, así como su concepción de la naturaleza y del mundo como fenómeno característico sigue creciendo y levantando cierta expectación. El conocimiento de los chamanes sobre las plantas medicinales para producir medicamentos ha sido más "práctico".

Los pueblos indígenas han ocultado su sabiduría botánica. Quizás por la desconsideración que ha recibido su modelo de salud, en este caso también etiquetada de supersticiosa y, ante el temor y la sospecha de que les fuese robado aquello que ellos consideran propio y de gran valía. Descola considera que sus conocimientos sobre la materia son más bien teóricos y teñidos de escepticismo, los mismos que levantan hacia los remedios que nosotros llevamos, lo cual responde al acercamiento que la población achuar tiene en el proceso de salud-enfermedad-atención (2005: 235).

En este sentido, las plantas medicinales no faltan en la comunidad achuar, alrededor de las casas se encuentran diferentes tipos de arbustos, matas y plantas que siembran las mujeres, no siendo por ello un conocimiento exclusivo de hombres. En no pocas ocasiones, los pacientes acuden a los puestos de salud con preparados que ellos mismos u otros han realizado y han aplicado, relatando haber tomado algún tipo de piri-piri ${ }^{25}$ inicialmente, o habiendo aplicado algún tipo de emplastos o cataplasmas en quemaduras, fracturas, luxaciones y lesiones dermatológicas.

El acercamiento empírico a la enfermedad se resuelve en gran parte en el interior de la unidad doméstica. Hasta hace unas décadas las mujeres y en menor medida los varones ancianos poseían un conjunto de prácticas diagnósticas y terapéuticas destinadas sobre todo al tratamiento de los sunkúr a partir de sus conocimientos botánicos. Vargas Canelos ${ }^{26}$ (1995: 34), señala que en su entorno se encuentran remedios

\footnotetext{
${ }^{24}$ Compilación de nombres genéricos publicados e integrados por el Código Internacional de Nomenclatura Botánica (para algas, bongos y plantas).

${ }^{25}$ Las plantas llamadas en español amazónico "piri piri" son hierbas que en la Amazonía (Perú y Ecuador) utilizan en medicina o en otros usos calificados de mágicos. Cada tipo tiene un uso determinado, y existen tantos tipos que el conjunto de ellos puede ser considerado una panacea (Tournon 1998). Plantas medicinales que a veces les cuesta reconocer ciertas variedades, la mayoría de las cuales parecen botánicamente idénticas (Descola 1996: 230). La población achuar refieren que hay una enorme variedad de piri-piris, cada uno de ellos con fines terapéuticos diferentes.

${ }^{26}$ Fundador de la OPIP (Organización de Pueblos Indígenas de Pastaza) y dirigente de la misma, fundador de la CONFENIAE (Confederación de Nacionalidades Indígenas de la Amazonia Ecuatoriana) y presidente de la misma, dirigente de la COICA (Coordinadora Indígena de la Cuenca Amazónica), fundador y presidente de la Organización de la NAE.
} 
vegetales para todo tipo de enfermedades sin tener que recurrir a la medicina occidental. Se relata un inventario de más de treinta plantas medicinales que los achuar cultivan, siendo el tabaco la planta que utilizan con fines verdaderamente terapéuticos, debido a sus efectos alucinógenos, y a la forma de aplicarla.

El énfasis que se le da a este tipo de terapias por lo de "natural", especialmente por las cualidades empíricas implicadas en los tratamientos herbolarios, cuyos análisis farmacológicos revelarían sin ninguna duda las virtudes curativas, se realiza a expensas de ocultar su dimensión mágico-religiosa (espiritual) y la eficacia simbólica que se le concede a cualquier medicina tradicional (Flores 2009: 469). En este sentido, más que terapias empíricas, aplican terapias "mágicas".

De igual forma a lo ocurrido con anteriores alternativas terapéuticas, se anuncia por parte de los foráneos, de agentes

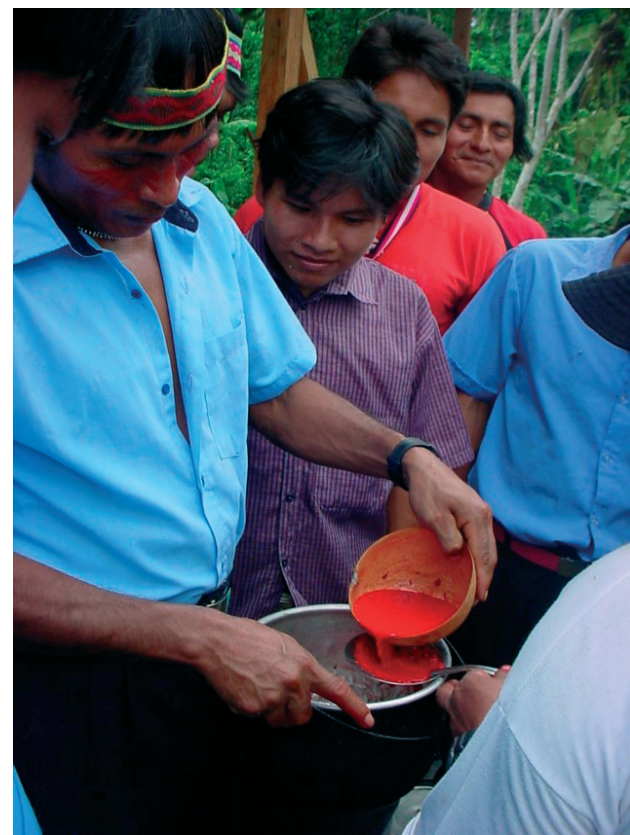

ImAGen 3.-Capacitación de Promotores en medicina tradicional. Fotografía de la autora. de desarrollo, que este tipo de prácticas botánicas han decaído de forma importante. Las causas, las encuentran en la influencia de la medicina occidental, de los contactos con comerciantes, misioneros... así como las presiones aculturativas que han hecho que se descuiden o se oculten diversas técnicas curativas, teñidas de trasnochadas, sépticas y poco científicas.

La medicina tradicional no existe, además ya no creen en ella, los chamanes no tienen importancia ni prestigio social. (Ruth, cooperante expatriada).

Este pronóstico trata de modificarse, recuperando los conocimientos botánicos que han sido ensalzados por diferentes organizaciones no gubernamentales, las cuales lanzan proyectos en esta línea. En este sentido, el proyecto de cooperación al que se hace alusión plantea como uno de sus principales objetivos, la constitución y capacitación de una red de promotores de salud. Para la culminación de dicho propósito se trata de realizar actividades que logren fortalecer a estas figuras de salud locales, para lo cual han sido capacitados en medicina tradicional achuar (además de otros ámbitos que veremos más adelante). Estas formaciones son realizadas por agentes de salud colonos, miembros de la contraparte y de la ONG que respalda el proyecto, por auxiliares de enfermería achuar y expertos locales en el tema, de procedencia peruana y expertos en medicina tradicional.

Los promotores de salud son una figura consustancial al proceso de salud, enfermedad y atención en Latinoamérica, agentes comunitarios que tradicionalmente han asumido tareas sanitarias. Cuentan con el reconocimiento de la comunidad, sobre todo por los conocimientos que poseen en torno a la salud y enfermedad, sobre plantas 
medicinales y sobre terapias mágico-religiosas que han adquirido o se les ha transmitido. Herederos visibles de este tipo de conocimientos botánicos entre otros y con relaciones filiales con algunos de los chamanes ocultos, representan al personal de salud local, autóctono, a priori sin formación biomédica y sin percibir remuneración económica de forma oficial y continuada. A pesar de ello, mantienen, al menos esporádicamente, sus tareas encomendadas.

En Ecuador, en un tiempo fueron integrados en el organigrama de salud y, por tanto, remunerados económicamente por el Ministerio de Salud. Se trata de una cuestión en continuo debate, así como su reconocimiento más allá del comunitario, su nivel de competencia, y de responsabilidad.

Por otro lado, desde la contraparte local se promueve el "desarrollo" de este pueblo a través de la explotación de plantas tradicionalmente usadas por ellos. Sugieren que se abran nuevos mercados con estos productos naturales, generándose un comercio en torno a estos artículos en forma de cosméticos, fitofármacos, bajo el formato de jabones, champús, cremas, aceites, esencias, geles de baño, geles para determinadas patologías, jarabes, ungüentos, bálsamos etc....respaldados con la consigna de medicina natural. Son elaborados con raíces y extractos de plantas que obtienen de la selva, para lo cual también se invierten recursos y se capacita al personal local. Hobart (2012: 93), señala que la entrega de la ayuda al desarrollo y la ampliación de mercados para los productos manufacturados, está más que compensada por los procesos de contradesarrollo. En este sentido y a través de estos procesos, los países a desarrollar constituyen la principal fuente de materias primas baratas y mano de obra, además de ser el conocimiento técnico una mercancía valiosa susceptible de ser vendida o transferida. Además, y para el caso referido, se cuestiona la existencia, el auge o la decadencia en el uso de las plantas medicinales, pues hay otras justificaciones en el acercamiento y la implantación de otros modelos de salud.

\section{LA INCORPORACIÓN DEL MODELO BIOMÉDICO A TRAVÉS DE LOS PROYECTOS DE DESARROLLO}

El gobierno ecuatoriano con sus propuestas legislativas en temas de salud, que de forma explícita se señalan en el artículo 32 de la Constitución de 2008, garantiza este derecho a través de sus políticas.

En esta arena política parte del protagonismo y de la responsabilidad es cedida a las agencias de cooperación. Se plantea el proyecto ya aludido, con líneas de acción como son la capacitación en medicina tradicional achuar y en medicina occidental, lo cual resulta revelador y significativo el sincretismo de dicho objetivo. Aquí, el conocimiento exhaustivo de las diferentes terapias y explicaciones sobre el origen de las enfermedades o males, es fundamental, así como el reconocimiento de las figuras de salud local, y de todo lo que puedan ofrecer, sin las cuales la inclusión de otros modelos de salud se torna artificioso.

Un país como Ecuador sin la cooperación no puede hacer nada, y más aún en el ámbito sanitario, es imprescindible para llevar a cabo actividades de desarrollo. (Director del Departamento de Cooperación Internacional, Ministerio de Salud Pública, Ecuador - Quito). 


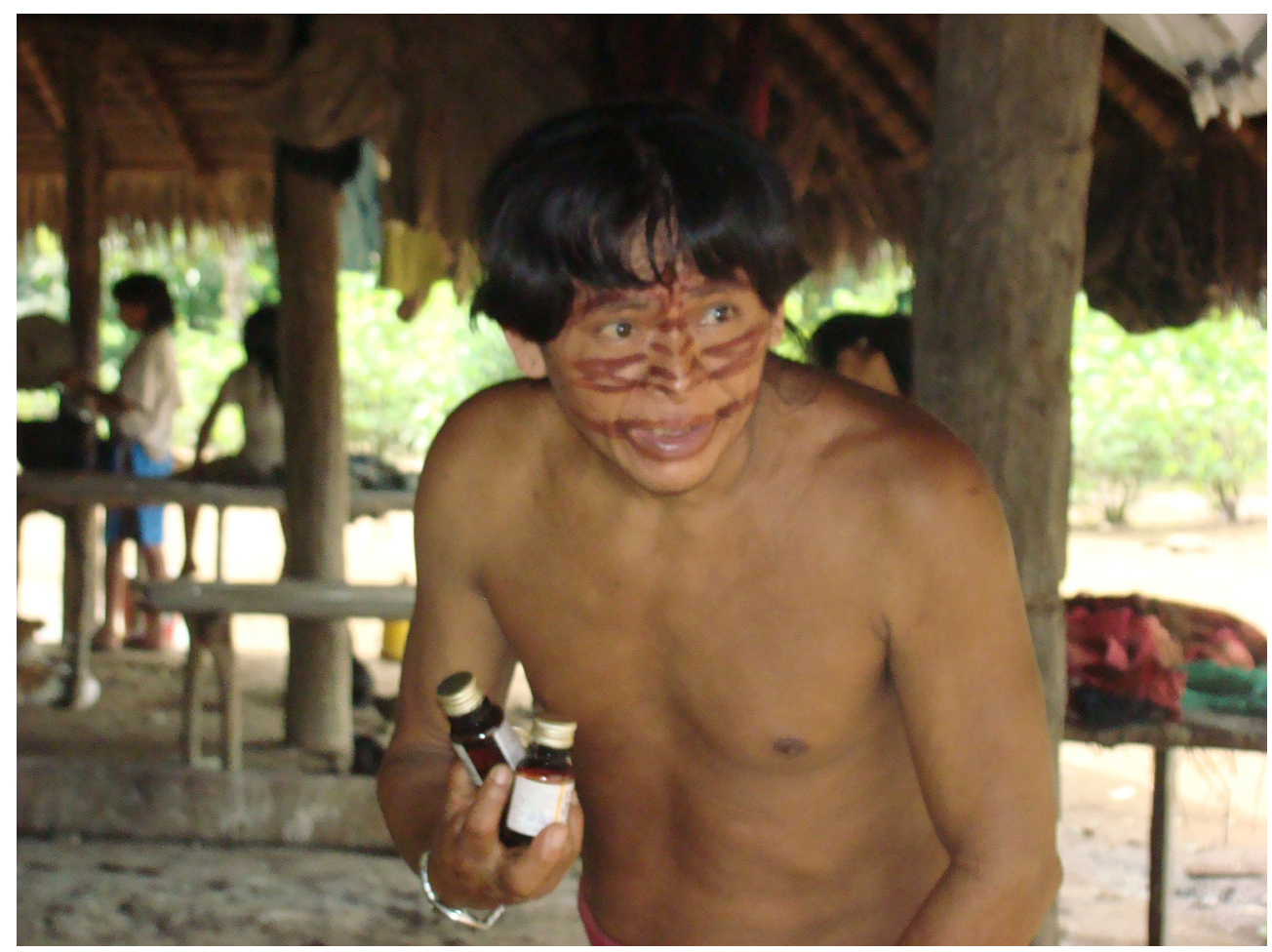

IMAGEN 4.-La medicina occidental, el tercer escalón de la medicina achuar.

Las capacitaciones son diversas: prevención e identificación de las enfermedades más prevalentes, técnicas de exploración, tomas de constantes vitales, registro de signos clínicos, empleo de gráficas de peso y talla... Se trata de inculcar la necesidad del uso de la historia clínica o la utilización de algún tipo de documento donde queden anotadas las actividades realizadas. Cabe recordar que la sociedad achuar es de tradición ágrafa, donde la lógica de la escritura se ha incorporado recientemente. Por otro lado, se instruye en el empleo de un vocabulario adecuado y oportuno, deben aprender a manejar la terminología biomédica, así como las indicaciones que desde este modelo se contemplan, con especial énfasis en la prescripción de fármacos. El personal sanitario local trata de adquirir el lenguaje médico en un intento de ser competente y poder conseguir el reconocimiento y el prestigio que de ellos se espera. Aij, el auxiliar de enfermería de la comunidad de Wichim, solicitaba colaboración para pedir la transferencia de uno de los pacientes de este modo:

La señora presenta —unos momentos de silencio, casi titubeando continua - ¿doloooorrrr vaginal? —se separa y me pregunta ¿cómo dicen ustedes, cómo digo... qué síntomas?

El proceso de capacitación en medicina occidental se hace visible a través del reparto de botiquines comunitarios. El botiquín en su acepción más generalizada, es el espacio destinado a contener medicamentos, en este caso al ser comunitarios, dichos 
fármacos son destinados para toda la comunidad. Además del lugar donde se guardan los fármacos, por botiquín entendemos todo el conjunto de estos medicamentos que se precisa para hacer una asistencia básica. El botiquín también es el emplazamiento donde se aplican las primeras atenciones, se hace asistencia "médica", en un porcentaje elevado de las ocasiones llevada a cabo por personal no médico. Tal y como lo evidencia Nadia, coordinadora del departamento de salud intercultural en la dirección provincial de Pastaza- Puyo, la presencia del fármaco se hace imprescindible para poder hacer asistencia.

Y luego ahí uno termina agarrando las vitaminas por último y al final lo menos agresivo... porque se sienten así o te dicen no cerraste la consulta, alguna cosa has de darle... pero para hacer eso, para que queden medio tranquilos es con la medicina... Te sientes mal sino les das medicina, te juro, es... algo falta en la consulta sino les das medicina, puede ser que hasta no la tome, pero la pide, yo pienso que es como el elemento formal de la consulta, médico, paciente, enfermera, escritorio, medicina es como algo obligatorio que debe estar ahí y, por otro lado, es la oportunidad de tener contacto con alguien más.

Rigoberto, promotor de salud con muchos años de experiencia lo refiere en estos términos: "Yo no hago nada, no tengo medicinas, así estoy en mi casa". En las evaluaciones sobre la atención sanitaria se detecta que los pacientes que no reciben medicinas no quedan registrados como pacientes atendidos.

En casi todas las comunidades hay promotor de salud, que no botiquines. La ubicación y el reparto de los mismos, como otra de las principales acciones de la ONG, y su asignación será motivo de discusión, en largas y distendidas reuniones, entre el personal de la ONG, la contraparte y los agentes de cooperación. Regentar un botiquín otorga poder. Como se ha referido, la actitud de la población achuar, también frente a este tipo de medicina por el que siente atracción por lo novedoso, es de escepticismo, la piden constantemente pero no siempre la toman, sin olvidar los efectos beneficiosos y simbólicos de la misma.

\section{NUEVOS ROLES, VIEJOS ACTORES. NUEVAS IDENTIDADES REESTABLECIDAS}

Los nuevos roles sociales que adquieren algunos de los pobladores indígenas achuar, con especiales énfasis en el personal de salud, incitados desde el marco de la cooperación al desarrollo, configuran un panorama de grandes cambios en su organización social, en ocasiones de forma rápida e intermitente. En este sentido, la falta de continuidad no permite tener una representación compartida de los significados, para que en concordancia con ello, las acciones sociales puedan ser interpretadas tal y como refiere Hendricks (1996: 174).

En este proceso de exigencia de nuevos (y viejos) roles, más comúnmente asignados a los varones achuar, tales como promotores de salud, profesores, auxiliares de enfermería, microscopistas, granjeros, dirigentes políticos, delegados de la $\mathrm{NAE}^{27} \ldots$ se acogen rasgos de la cultura dominante sin por ello subordinar la suya.

\footnotetext{
${ }^{27}$ En otros tiempos fueron otros roles los asumidos por los pobladores achuar, como el de catequistas dependientes de las organizaciones religiosas. Tal y como lo señala Gutiérrez (2009: 4) estos nuevos líderes han tenido un pasado de militancia "religiosa", en el sentido que han recibido formación desde las estructuras religiosas que perduran.
} 


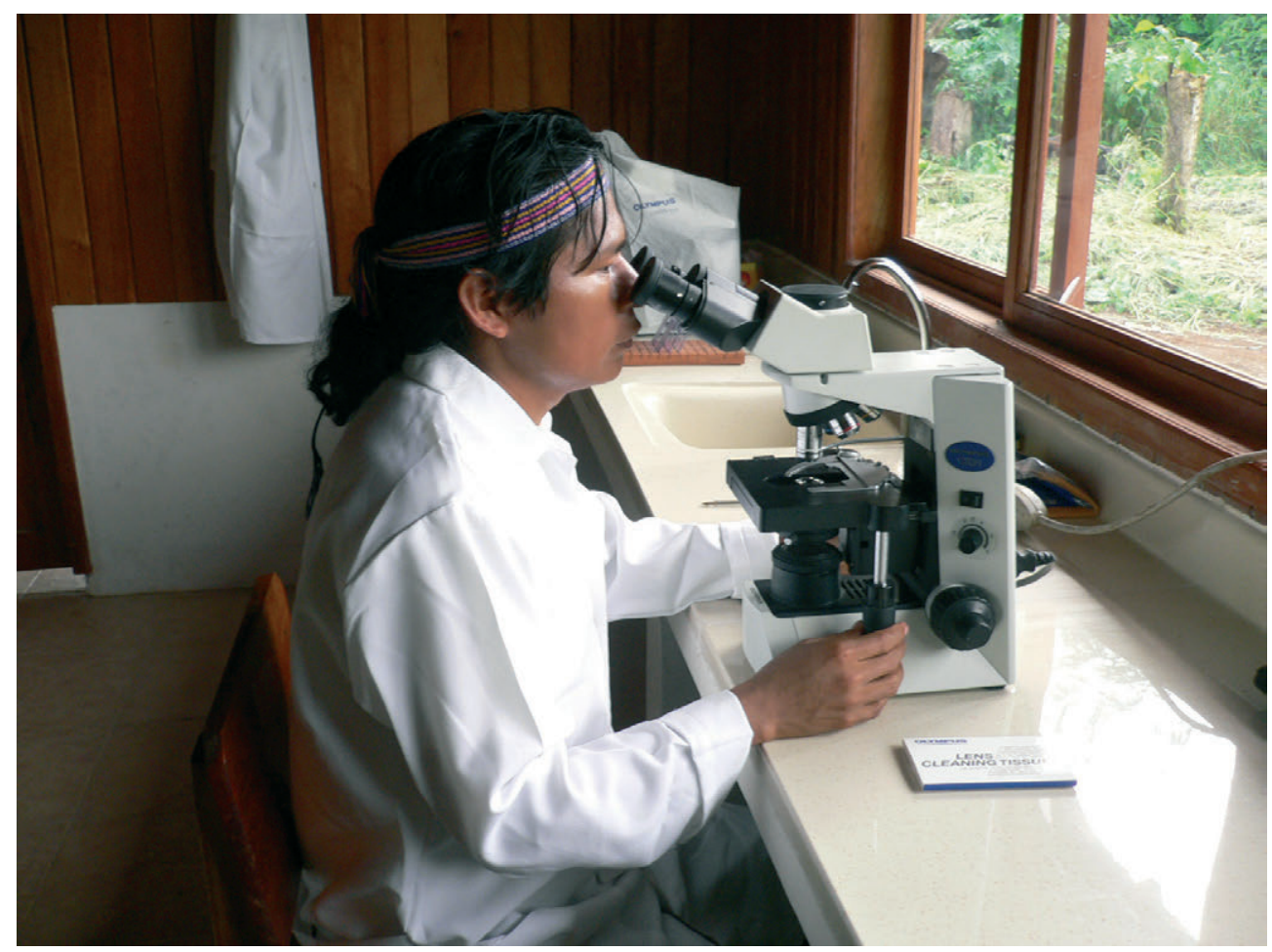

IMAGEN 5.-Personal de salud local a medio camino entre las dos esferas de la medicina occidental y la medicina tradicional. Conocen y manejan ambos enfoques, han recibido formación paramédica y su identidad cultural presente les hace tener que manejar situaciones ambiguas para ellos.

Las relaciones que establecen muchos de sus pobladores con el mundo de "fuera", el contacto con la sociedad nacional, ha derivado en la adopción de un sistema altamente estructurado. Su situación les hace tener que marchar "fuera" a diferentes cometidos: cursos de formación, firma de contratos, cobro de sueldos, recogida de fármacos para la farmacia que gestionan, reuniones... Estas personas disponen de un mayor acceso a determinados recursos en auge. Las salidas también se emplean para adquirir productos que dentro son "Valiosos", bien para la familia o para su venta. Se aprovecha para hacer visitas, para ir al chamán, para tomar un trago, o para ir al mercado.

Estos trasiegos y "Viajes" les permiten ir adquiriendo competencias para desenvolverse en esta nueva realidad. En este sentido, Muratorio (1996: 389) considera que la entrada en el sistema capitalista por parte de estos pueblos indígenas, les ha permitido liberarse de los viejos sistemas de dominación. Para la sociedad achuar están siendo "nuevos" tiempos — llevan siéndolo mucho tiempo-. Desplazan sus actividades de abastecimiento y sus relaciones sociales que tratan de mantener de diversas formas bajo la premisa de "seguir siendo iguales" en términos de López y Gutiérrez (2009: xvi). Y ello no sólo por la visión de provisionalidad en dichos cargos, sino también porque en la dependencia personal con su comunidad está su fuerza, entendiendo 
que si la reciprocidad se debilita, su prestigio está en cuestión. Ante las nuevas funciones, estos nuevos "grandes hombres" en términos de Godelier (1982), disponen de menos tiempo para tareas valoradas como es la caza, la construcción de casas o el cuidado del ganado. Han incorporado actividades que les hacen marginar parte de su "Cotidianidad", siendo relegadas estas rutinas a otros vecinos a cambio de dones, regalos, cartuchos para la caza, atención sanitaria, mercancías llegadas de fuera, alimentos envasados, pilas, baterías, medicamentos, etc... Tratan de cultivar las relaciones sociales, cuidan sus reuniones protocolarias y oratorias impactantes, indicadoras de fuerza espiritual. Estas relaciones sociales se traducen en habilidades para mantener o adquirir nuevas alianzas, productoras de jerarquías de poder, y generadoras de nuevas estructuras sociales.

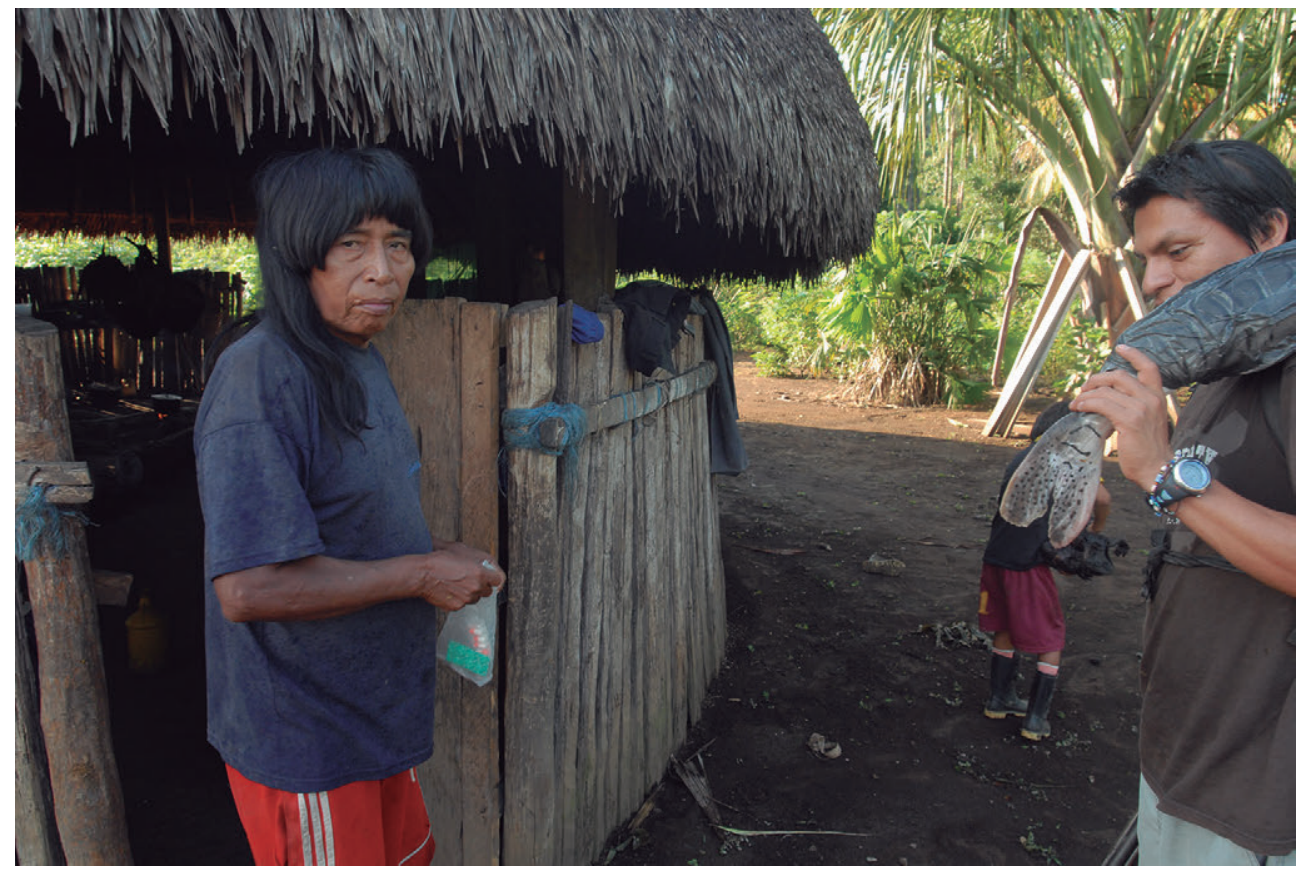

Imagen 6.- Intercambio de dones entre el personal de salud y la población. Fotografía de la autora.

De una forma general, este fenómeno que algunos integran en la globalización ha relativizado las fronteras étnicas, también las nacionales, ha creado identidades más complejas, obligando a replantear las relaciones dentro de las propias comunidades y entre ellas. La prosperidad no es atribuida a su poder personal, ligado a la interpretación de visiones, conocimiento chamánico, sino que se asocia con la educación formal y su habilidad para manejarse en las nuevas estructuras sociales e ideológicas, obteniendo un poder distinto a las formas tradicionales y que justifica las relaciones de dominación asociadas a él. Hendricks (1996: 150) apunta que las nociones de poder expresadas en los discursos validan las estructuras ideológicas tradicionales y las transforman para generar nuevas. 
Sobre ello reflexiona Ceferino Chumap, profesor y director del centro universitario salesiano en Wasakentsa.

Hay un problema con la llegada de roles, hay una contaminación que viene de fuera, yo ahora soy profesor, soy el enviado de la organización, los roles están muy establecidos, no necesito ir a cazar y tengo un poder.

En el mismo sentido, convergía la licenciada Lya, al evidenciar esta transformación:

Es que la organización social ya está cambiando, ya tienen un organigrama, antes el líder ha sido el mayor, el guerrero, hoy el líder es el que selecciona la asamblea, o es el presidente.

Las nuevas estructuras de poder, generan situaciones desiguales, también entre la población local, emergiendo reacciones y estrategias tanto acomodaticias como de resistencia. De forma particular, presentan sus propias categorías de significado y su manera de explicar y procesar la información recurriendo a formas del lenguaje conocidas. De forma evidente, se aprecia en el modo de interpretar su proceso de enfermar, de describir la forma de prevenirlo y resolverlo. El repertorio de términos empieza a formar parte también del léxico de la población, aprenden qué signos y síntomas deben expresar, para conseguir lo que la medicina que trata de imponerse como hegemónica puede ofrecerle. Esta jerga la reconocen como necesaria, saben que es lo que da credibilidad, en ocasiones sin entender el sentido ni el significado de la misma. Del mismo modo que el personal de salud, la población local incorpora las estrategias y el lenguaje necesario. Los relatos en las consultas, los registros de diagnósticos y los tratamientos realizados por el personal de salud local dan muestra de ello de forma muy significativa. En este sentido, en una ocasión llegó un varón al puesto de salud y al preguntarle que le pasaba, de forma sosegada contestó: "Tengo dolor de ovarios".

Se apropian del lenguaje público, un lenguaje proporcionado por el Estado, por ONG y por las misiones entre otros. También adquieren habilidades para participar en los procesos de desarrollo que se realizan en su propio territorio y de los cuales, todavía ahora quedan alejados. Gutiérrez y López (2009: xix) entienden que los proyectos de desarrollo se presentan como vectores ideológicos de Occidente, llegados a otras sociedades de distinta manera: religiosos, económicos, políticos. Sentencian que el proyecto de desarrollo, es actualmente el documento que mejor relata la relación indígena-no indígena. Con respecto a la población local, a pesar de haber enfatizado la relevancia de "primero la gente" (Sen y Kliksberg 2007), siguen ocupando lugares anecdóticos sin que por ello desistan y sigan reivindicando su lugar. Las contrapartes que movilizan a la comunidad capitaneadas por los nuevos dirigentes que se erigen, y que son los que mantienen el contacto con los agentes de desarrollo y con las organizaciones y financiadores, consiguen y mantienen una relación de clientelismo, demandan este tipo de ayudas, con objetivos más próximos a su realidad, como pueda ser su personal promoción y reconocimiento social.

Nadie sabe nada de los proyectos, del dinero que mandan, no sabemos cuánto han costado las casas, no dicen nada a los achuar que son los interesados, a mí me preguntan todo porque trabajo aquí y yo no sé nada, porque yo sólo soy un trabajador del Ministerio. (Masinkias, Auxiliar de enfermería). 
Los nuevos vínculos establecidos con los agentes y agencias de cooperación al desarrollo, concretamente en el campo de la salud, en las relaciones sociales achuar, a nivel económico incluso político-religioso, con procesos adaptativos, con modificaciones, y variaciones, conforman un nuevo mundo achuar. Parece que es relativamente frecuente la aparición de nuevas estrategias transigentes, a las también constantes nuevas comunicaciones y afinidades, lo que no evita que se genere un horizonte desestructurado. En este sentido Gutiérrez (2009:8) asevera que entre la población indígena, las nuevas identidades surgen por doquier y las viejas se redefinen.

\section{LA PERMEABLE RELACIÓN DEL ESTADO CON LAS AGENCIAS DE COOPERACIÓN Y SU ETERNA FRAGILIDAD}

Asad y Kay (2015) señalan que la relación Estado-agencia es más que necesaria. Para el caso ecuatoriano queda expuesto por los responsables de ambos universos: el estado necesita de las ONG para el aporte de recursos, y estas necesitan de aquellos para facilitar las entregas. Se eluden análisis que, si bien parecen sencillos, evidencian la dificultad de poner sobre la práctica la necesidad de dicha afinidad (Pulido 2014; Mosse 2013; Unceta 2013). A pesar del discurso crítico del que parten las ONG, para mantener su vigencia o supervivencia, se encuentran limitadas por los sistemas burocráticos de la cooperación oficial, por lo que pueden llegar a actuar como una empresa convencional. Por otro lado, considerar la labor de la cooperación internacional y las ONG como un mecanismo de reproducción del sistema capitalista, tal y como lo reflejan Petras y Vieux (1995), deja en evidencia no solo el discurso sobre la solidaridad, sino también las actitudes de las que parten las ONG de lucha social, afirmando que al lado de los gobiernos no pueden mantenerse.

El gobierno ecuatoriano se encuentra en una coyuntura, dado el respaldo legislativo que ha otorgado a los modelos de salud tradicionales, que sigue potenciando y respaldando bajo el término genérico de interculturalidad, y con categorías como la del buen vivir incluidas en el texto constitucional, en tanto que símbolo de una concepción del desarrollo más sostenible y más respetuosa con el acervo cultural e identitario de las poblaciones indígenas. Y ello poniendo de manifiesto empíricamente las dudas ya planteadas por Bourdieu (2001: 153) sobre las dificultades para llevar a cabo este tipo de planteamientos dada su imprecisión conceptual y ambigüedad. Respondiendo según Viola (2014: 64) a una "tradición inventada" en el sentido que Eric Hobsbawm la define. Ello no se aleja de los modelos macroeconómicos incompatibles con el tipo de valores que se promueven, donde quedan incluidas las agencias de cooperación y el peso específico que sigue teniendo el modelo occidental, y en el ámbito de la salud en particular. A partir de aquí, se busca la inclusión de todas las identidades culturales, se reconoce la diversidad bajo el paraguas de la homogenización, tratando de encontrar una convivencia armoniosa (Ramírez Hita 2014). Es lo que Diaz Polanco (2005) entiende como "etnofagia", produciendo una mayor reactivación de dichas identidades.

Vivimos momentos de "crisis" donde según Grasiot (2015), la disminución de la financiación y la introducción de la empresa privada, como agente de la cooperación, apuntan a una transformación de la política pública de la cooperación al desarrollo. Pero 
no parece que sea tal, sino que quizás esa "crisis" es intrínseca y característica de estas instituciones. La necesaria tecnificación y profesionalización, así como la adquisición de un discurso crítico, les deja como única salida quedarse con los motivos ideológicos.

Tal y como sugieren Abramowitz y otros (2015), deberíamos comenzar a plantearnos de nuevo cuestiones tan fundamentales, tan básicas y tan necesarias como las que los antropólogos que participan en el estudio sugieren y reconocemos es el punto de partida en los proyectos de desarrollo: ¿Cómo implican las agencias a la comunidad?, ¿Quién es la comunidad? ¿Qué obligaciones, como antropólogos u observadores externos, tenemos con la "comunidad"?, ¿Quién está haciendo las políticas?, ¿Cómo se vincula al mundo local?, ¿Qué intereses están siendo representados?, ¿Quién está siendo marginado y borrado?, ¿Cómo es la racionalidad técnica de las grandes agencias internacionales que distorsionan el mundo moral? Es fundamental alejarse del pensamiento dual y dividido que persiste en el panorama humanitario (donante / receptor, expatriado / local, ONG / estado, donante / beneficiario, biomédico/tradicional), analizarlo de forma compleja incluyendo toda la gama de actores así como sus formas de entender los procesos de salud, enfermedad y atención.

Los diálogos y contrastes que aparecen a lo largo del texto, tratan de acercarse a las relaciones que se establecen entre los diferentes intérpretes que participan con los diferentes modelos de salud y sus correspondientes figuras. Todo ello promovido por unos códigos y lógicas propias, alejadas y distantes de los principios que justifican cada uno de los sistemas de salud, singulares entre sí y con matices que confluyen. Aquí se encuentra la riqueza y la consistencia de los mismos, lo que hace necesario disponer de las claves para su entendimiento.

\section{BIBLIOGRAFÍA CITADA}

Abad González, Luisa. 2003. Etnocidio y Resistencia en la Amazonía Ecuatoriana. Cuenca: Ediciones de la Universidad de Castilla-La Mancha.

Asad, Asad L. y Tamara Kay. 2014. "Theorizing the Relationship Between NGOs and the State in Medical Humanitarian Development Projects". Social Science and Medicine 120: 325-333.

Asad, Asad L. y Tamara Kay. 2015. "Toward a Multidimensional Understanding of Culture for Health Interventions". Social Science and Medicine 14: 79-87.

Abramowitz, Sharon, Meredit Marten y Catherine Panter Brick. 2015. "Medical Humanitarianism: Anthropologists Speak Out on Policy and Practice". Medical Anthropology Quarterly 29(1): 1-23.

Bolla, Luis. 1991. Achuar Matsátmau. Mundo Achuar 1. Lima: Centro Amazónico de Antropología y Aplicación Práctica (CAAAP).

Bolla, Luis. 1993. El pueblo de la "Wayús": los Achuar. Achuar Matsátmau 2. Lima: Editorial Salesiana.

Bolla, Luis. 2003. Los Achuar: Sub-Etnia del pueblo de los Aínts o Jíbaros. Achuar Matsátmau 4. Lima: CAAAP.

Bourdieu, Pierre. 2001. Las estructuras sociales de la economía. Buenos Aires: Manantial.

Calavia Sáez, Oscar. 2004. "La barca que sube y la barca que baja. Sobre el encuentro de tradiciones médicas", en Gerardo Fernández Juárez (coord.), Salud e interculturalidad en América latina. Perspectivas antropológicas: 169-218. Quito: Abya Yala.

Carneiro da Cunha, Manuela. (1998). "Pontos de vista sobre a floresta amazônica: xamanismo e tradução". Mana 4(1): 7-22.

Chaumeil, Jean Pierre. 2004. "Del proyectil al virus. El complejo de dardos mágicos en el chamanismo del oeste amazónico", en Gerardo Fernández Juárez (coord.), Salud e interculturalidad en América latina. Perspectivas antropológicas: 265-279. Quito: Abya Yala. 
Descola, Philippe. 1996. La selva culta. Simbolismo y praxis en la ecología de los Achuar. Ecuador: Abya-Yala.

Descola, Philippe. 2005. Las lanzas del crepúsculo. Relatos jíbaros alta Amazonía. Buenos Aires: Fondo de Cultura Económica.

Díaz-Polanco, Héctor. 2005. "Etnografía y multiculturalismo". Disponible en: <http://www.estudiosecologistas.org/docs/reflexion/indigenas/etnofagia.pdf.>. Fecha de acceso: 30 nov. 2015.

Fabre, Alain. 2005. "Diccionario etnolingüístico y guía bibliográfica de los pueblos indígenas sudamericanos". Disponible en: <http://www.ling.fi/Entradas\%20diccionario/Dic=Quechua.pdf $>$. Fecha de acceso: 26 sept. 2016.

Fast, Gerhard y Ruby Fast. 2008. Introducción al idioma Achuar. Lima: Ministerio de EducaciónInstituto lingüístico de Verano.

Flores, Juan Antonio. 2004. "Una etnografía del "año de provincias" y de "cuando no hay doctor". Perspectivas de salud intercultural en Bolivia desde la biomedicina convencional", en Gerardo Fernández Juárez (coord.) Salud e interculturalidad en América latina. Perspectivas antropológicas: 181-213. Quito: Abya-Yala.

Flores, Juan Antonio. 2009. "Patrimonialización de la cultura indígena y tradicional en Bolivia y México: la UNESCO y los efectos no deseados en la medicina Kallawaya y el día de los muertos", en Julián López García y Manuel Gutiérrez Estévez (coords.), América indígena ante el siglo XXI: 469-499. Madrid: Fundación Carolina.

Flores, Juan Antonio. 2011. "Interculturalidad en salud y eficacia: algunas indicaciones de uso para OGND con proyectos de salud en América Latina". Nuevo Mundo Mundos Nuevos, Debates, [En línea], Puesto en línea el 31 marzo 2011. Disponible en: <http://nuevomundo.revues.org/61232>. Fecha de acceso: 26 sept. 2016.

Godelier, Maurice. 2011 [1982]. La produccion de los grandes bombres: Poder y dominación masculina entre los Baruya de Nueva Guinea. Madrid: Akal.

Good, Byron J., Mary-Jo DelVecchio Good, Sharon Abramowitz, Anthur Kleinman y Catherine PanterBrick. 2014. "Medical Humanitarianism: Research Insights in a Changing Field of Practice". Social Science and Medicine 120: 311-316.

Grasiot, Esther Oliver 2015. "ONG, crisis económica e ideología. Aproximación a los efectos de los "recortes" a través del estudio de caso de la ONG AlterNativa. Intercanvi amb els Pobles Indígenes". Periferia 20(1): 56-84.

Hendricks, Janet 1996. "Poder y conocimiento: discurso y transformación ideológica entre los Shuar", en Fernando Santos Granero (comp.), Globalización y cambio en la Amazonía indigena: 131183. Volumen I. Quito: Abya Yala.

Hobart, Mark. 2012. "Introducción ¿El crecimiento de la ignorancia)", en Beatriz Pérez Galán (ed.), Antropología y desarrollo. Discurso, prácticas y actores: 92-121. Madrid: Los Libros de la Catarata, IUDC (UCM).

Instituto Lingüístico de Verano. 1996. El Diccionario Achuar-Shiwiar Castellano. Perú: Ministerio de Educación.

López, Julián y Manuel Gutiérrez (coords.). 2009. América indígena ante el siglo XXI. Madrid: Siglo XXI/Fundación Carolina.

Malinowski, Bronislaw. 1974. Magia, ciencia, religión. Barcelona: Ariel.

Michaux, Jacqueline. 2004. "Hacia un sistema intercultural de salud en Bolivia. De la tolerancia a la necesidad sentida", en Gerardo Fernández Juárez (coord.), Salud e interculturalidad en América Latina: 107-129. Quito: Abya Yala.

Mosse, David. 2013. "The Anthropology of International Development". Annual Review of Anthropology 42: 227-246.

Pulido, Montserrat. 2014. Otros colonialismos: la cooperación al desarrollo en programas y/o proyectos de salud. Medicinas en cuestión y medicinas en promoción en un contexto amazónico ecuatoriano. Tesis doctoral: Universidad Complutense de Madrid. Disponible en: <http://eprints.ucm.es/24655/ 1/T35183.pdf>. Fecha de acceso: 26 sept. 2016.

Pulido, Monsterrat. 2016. "Los dilemas propios de una investigación cualitativa en el ámbito de la cooperación al desarrollo: una cuestión delicada”. Acta Bioéthica (en prensa).

Ramirez Hita, Susana. 2014. "Health, Globalization and Interculturalism: an Anthropological Approach to the Situation of Indigenous Peoples in South America”. Ciência E Saúde Coletiva 19 (10): 4061-4069. 
Sánchez, Irene, 2015. Catequistas, líderes evangélicos y comunidad en localidades tojolabales de las Margaritas, Chiapas, México. Tesis Doctoral: Universidad Autónoma de Madrid.

Sen, Amartya y Bernardo Kliksberg. 2007. Primero la gente. Una mirada desde la ética del desarrollo a los principales problemas del mundo globalizado. Barcelona: Ediciones Deusto.

Taylor, Anne-Christine. 1996. "La riqueza de Dios. Los Achuar y las misiones", en Fernando Santos (ed.), Globalización y cambio en la amazonía indígena. Volumen I: 219-261. Quito: Abya Yala.

Tournon Jacques, Samuel Caúper y Rafaerl Urquía. 1998. "Los "piripiri”, plantas paradójicas de la Amazonía". Antropológica 16: 215-240

Unceta, Koldo. 2013. "Cooperación para el desarrollo: anatomía de una crisis". Íconos-Revista de Ciencias Sociales 47: 15-29.

Uriarte, Luis. 2007. "Los Achuar", en Fernando Santos y Federica Barclay (eds.), Guía Etnográfica de la Alta Amazonía. Volumen VI: Achuar, Candoshi: 5-243. Lima: Instituto Smithsonian de Investigaciones tropicales, Instituto Francés de Estudios Andinos (IFEA).

Ventura i Oller, Montserrat. 2008. "Chamanes amerindios: mediadores y traductores. Inx: Intelectuales, mediadores y antropólogos. La traducción y la reinterpretación de lo global en lo local". XI Congreso de Antropología: retos teóricos y nuevas prácticas: 207-220. San Sebastian: Ankulegi.

Viola, Andreu. 2014. "Discursos "pachamamistas" versus políticas desarrollistas: el debate sobre el sumak kawsay en los Andes". Íconos-Revista de Ciencias Sociales 48: 55-72.

Warren, Patricio. 1994. "Representaciones cognitivas y administración social de las enfermedades en los Jívaros-Achuar" en Patricio Warren, Carmen Hess, y Emilia Ferraro (eds.), Salud y antropologia: 7-38. Quito: Abya-Yala.

Fecha de recepción: 15 de enero de 2016.

Fecha de aprobación: 27 de junio de 2016. 